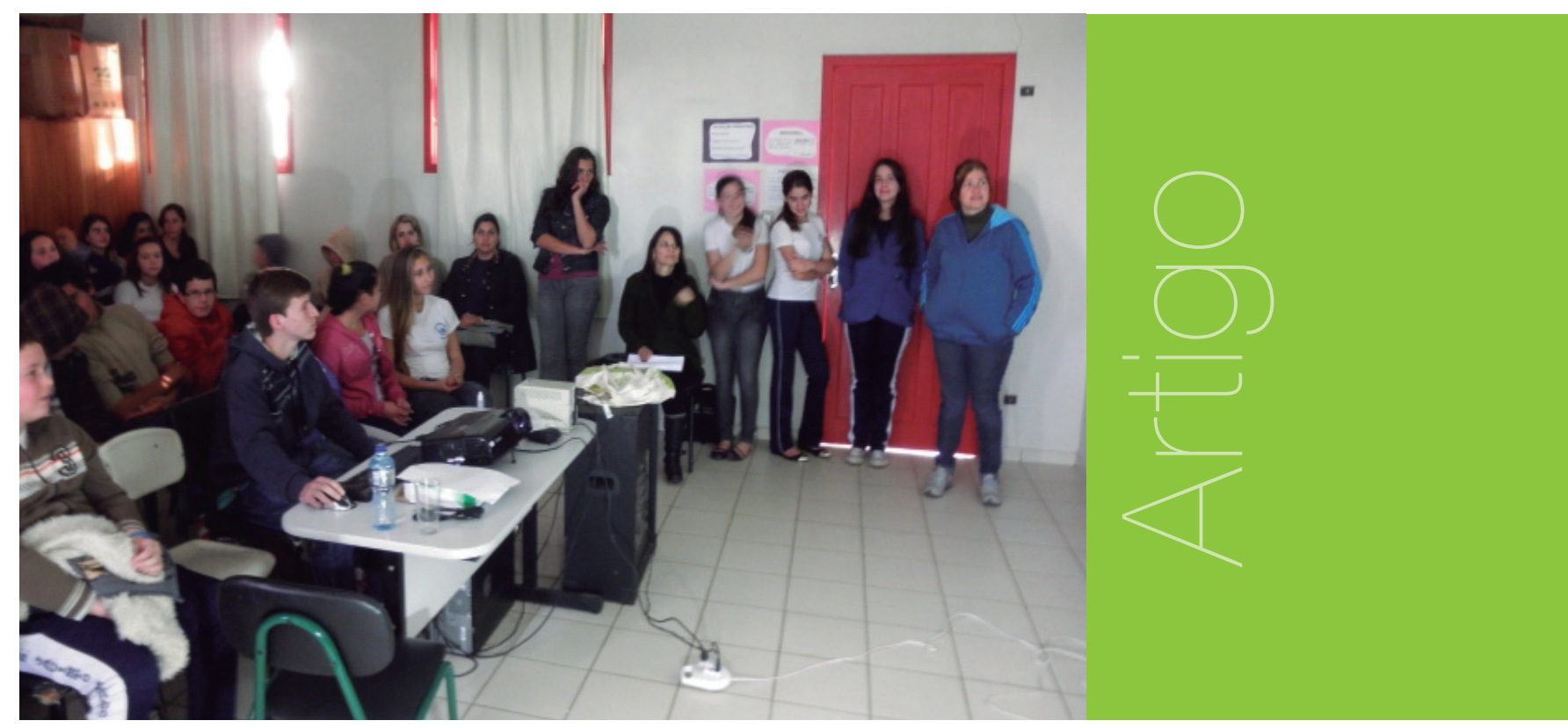

\title{
Ensino, docência e ferramentas didáticas: instrumentações da prática do professor de História no interior da Amazônia
}

\author{
Francivaldo Alves Nunes - fan@ufpa.br \\ Lêda Maria Nunes Ferreira² - ledamaria22@yahoo.com.br
}

\section{RESUMO}

0 presente texto apresenta os resultados do projeto "Interfaces do ensino e docência: produção de ferramentas e instrumentação da prática do professor de História no interior da Amazônia", desenvolvido no Campus de Cametá e vinculado ao Programa Integrado de Apoio ao Ensino, Pesquisa e Extensão (PROINT) da Universidade Federal do Pará (UFPA) em 2010 e 2011. Com a proposta de assegurar 0 desenvolvimento de atividades associadas à formação de novos aportes metodológicos no ensino de História, procurou-se demonstrar que as atividades vinculadas à extensão estavam associadas ao princípio de que a formação do licenciando deve ser orientada pelo conhecimento das condições concretas da escola, pela história dos seus sujeitos-educandos e do contexto social que os indivíduos e a instituição estão inseridos.

\section{PALAVRAS-CHAVE}

Ensino; Docência; História; Amazônia.

\section{ABSTRACT}

This paper present the results of the project "Interfaces education and teaching:production tools and instrumentation practice professor of history within the Amazon", developed at Campus Cameta and linked to the Integrated Support Programme for Education and Research extension (PROINT) of the Federal University of Para (UFPA) in 2010 and 2011. Proposing to ensure the development of associated activities to the formation of new methodological contributions in teaching history, sought to demonstratet hat the activities were linked to the extension principle

\footnotetext{
1 Doutor em História Social pela Universidade Federal Fluminense - UFF, professor na Universidade Federal do Pará (UFPA).

2 Graduada em História, professora da Secretaria de Estado de Educação do Pará (SEDUC).
} 
associated with that the formation of licensingin History must be guided by knowledge of the specific conditions of the school, the history of their subject-learners and the social context that individuals and institutions are inserted.

\section{KEYWORS}

Ensino; Docência; História; Amazônia.

\section{Introdução}

0 projeto "Interfaces do Ensino e Docência: Produção de Ferramentas e Instrumentação da Prática do Professor de História no Interior da Amazônia" se constituiu na materialização do saber acadêmico produzido nas discussões presentes no processo formador dos graduandos do Curso de História do CÂmpus Universitário do Tocantins/Cametá. Ao fazer uso dos conhecimentos obtidos na academia, o projeto possibilitou a estes alunos o diálogo com professores da rede pública e privada de ensino, compartilhando estes saberes com as práticas docentes acumuladas pelos anos de experiência em sala de aula, numa relação dialógica de ensino, em que pese a aproximação entre a construção do conhecimento formal e a realidade e interesse social.

Diante de um quadro educacional em que se observa um permanente crescimento do saber científico, não era de se estranhar que esse crescimento estivesse sendo acompanhado do aparecimento de especificidades tecnológicas. Sendo assim, na transposição do conhecimento histórico para a educação básica é relevante o desenvolvimento de competências ligadas à leitura, análise, contextualização e interpretação das diversas fontes e testemunhos das épocas passadas - e também do presente. Nesse exercício, devem-se levar em conta os diferentes agentes sociais envolvidos na produção dos testemunhos, as motivações explícitas ou implícitas nessa produção e as especificidades das diferentes linguagens e suportes através dos quais se expressam (PINSKY, 2006, p. 18). Estas situações evidenciam a necessidade do uso dessas novas tecnologias na produção de materiais didáticos que facilitem o processo de ensino-aprendizagem, conforme apontam os Parâmetros Curriculares, quando destaca os sentidos do aprendizado nas Ciências Humanas e suas tecnologias (BRASIL, 1999).

Ao propor a construção de ferramentas facilitadoras da prática docente, trabalha-se com as intenções apontadas pelas diretrizes curriculares que norteiam a educação básica, ou seja, a produção de materiais didáticos não só deve ser pensada numa perspectiva a associar esses materiais as novas tecnologias da informação, como internet, jogos, vídeos e outras mídias eletrônicas, como ainda em articular essas novas tecnologias ao desenvolvimento de materiais didáticos que dialoguem com a realidade regional das comunidades que ocupam 0 interior da Amazônia (CORREA, 1999, p.17). Neste aspecto, proporcionou-se aos alunos aproximar os conceitos e teorias, apropriados durante os estudos de graduação, das características da sociedade, assegurando com isso, significado para aquilo que era produzido no espaço acadêmico.

Ainda na relação universidade e sociedade foi possibilitado, aos professores atuantes da rede pública e privada, que exercem suas funções na educação básica, a apropriar-se desses novos conceitos, reelaborando suas práticas docentes e repensando a própria produção dessas ferramentas de trabalho e a configuração desses materiais didáticos. Assim, estabeleceu-se 0 que se chama de indissociabilidade entre ensino, pesquisa e extensão, uma vez que se entende que a formação profissional só adquire significado na medida em que não se desvincula das experiências e problemáticas presentes na sociedade (TARDIF, 2002, p.56).

0 projeto se configurou, de fato, enquanto atividade de extensão e ação comunitária. Além disso, procurou se sustentar conceitualmente, a propósito de que a construção de um profissional com autonomia, proposta principal dos cursos de licenciatura, tem que priorizar uma formação mais ampla que prepare os formandos para atuarem com criticidade, com capacidade de lidar com a diversidade cultural, de posicionarem-se diante das situações sociais, políticas e com condições de desenvolver escolhas conscientes sobre a maneira como irão desenvolver seu trabalho (PINSKY, 2006).

Desenvolvida em áreas de abrangência do Câmpus de Cametá da Universidade Federal do Pará (UFPA), região Nordeste do Pará, buscou-se identificar as necessidades dos professores da educação básica em lidar com o conhecimento formal e o processo de construção do 
conhecimento. Nesse caso, se oportunizou ao futuro docente e pesquisador o desenvolvimento de competências e habilidades para o desempenho de suas funções, uma vez que o mesmo esteve em contato com as condições sociais envolvendo o ensino e aprendizagem na região.

Além disso, permitiu que os docentes vivenciassem situações de forma interdisciplinar e atuassem de maneira a analisar o contexto social e direcionar programas e projetos que se integrassem às necessidades do momento. Além do que, permitiu a articulação de saberes desenvolvidos nos cursos e as necessidades sociais, conforme é destacado posteriormente.

\section{Metodologia}

0 projeto objetivou a construção de atividades associadas à produção de ferramentas e instrução da prática docente em História por meio da elaboração de materiais didáticos como cartilhas, textos, banco de imagens, planilhas e softwares. Foram envolvidos professores do ensino superior, alunos de graduação e professores da educação básica correspondente aos municípios de atuação do Câmpus de Cametá, a exemplo de Cametá, Mocajuba, Baião, Limoeiro do Ajurú e Oeiras do Pará.

Desenvolvido pela Faculdade de História, teve por base o princípio da indissociabilidade entre ensino, pesquisa e extensão e a tomada da diversidade como eixo estruturante da maneira diferenciada de se promover as temáticas previstas nas diretrizes da educação básica e associadas aos conhecimentos de História Antiga e Medieval, Moderna e Contemporânea e História do Brasil e Amazônia. As temáticas foram apresentadas a partir de uma perspectiva de valorização dos saberes locais.

Assim, todas as ações partiram do princípio de que as abordagens teóricas descritas em linguagens científicas precisam ser interpretadas e redimensionadas nos seus diferentes aspectos para que esse novo saber formal, produzido e apropriado pelos alunos do ensino superior, alcance os diferentes níveis de ensino das instituições públicas e privadas. Nesse caso, acredita-se que o desenvolvimento do projeto contribuiu na produção e publicidade de estratégias didáticas e pedagógicas para o ensino de História, estabelecendo uma relação entre o saber acadêmico e a experiência docente.

A primeira ação do projeto foi a realização de duas reuniões com os bolsistas envolvidos, ainda no final do primeiro semestre 2010. Estas reuniões foram pautadas pela explicação da proposta geral do projeto e das atividades a serem desenvolvidas. Em um segundo momento, objetivouse a organização e apresentação da proposta para a comunidade acadêmica, quando então 0 projeto foi exposto no IV Seminário de Extensão do Câmpus Universitário do Tocantins/Cametá, realizado dia 29 de outubro de 2010, na cidade de Cametá. Na oportunidade 0 coordenador do projeto apresentou os bolsistas e destacou as principais propostas a serem desenvolvidas com a implantação do Programa Integrado de Apoio ao Ensino, Pesquisa e Extensão (PROINT) na Faculdade de História.

Após a apresentação do projeto para a comunidade acadêmica, por meio do Seminário de Extensão, os alunos bolsistas iniciaram as atividades para preparação com os professores que iriam atuar como técnicos do projeto, principalmente na execução de oficinas de produção de materiais didáticos. Posteriormente foram realizadas as primeiras reuniões, classificadas como "preparatórias", onde tratava-se de encontros de planejamento de atividades do projeto. Foram realizadas duas reuniões com a presença dos docentes da equipe técnica, coordenação e bolsistas.

No primeiro semestre de 2011 as atividades se concentraram nos encontros de formação, que tiveram carga horária de 20 horas. As temáticas dos encontros envolviam discussões teóricas e metodológicas sobre o ensino e aprendizagem, os conceitos mais gerais de educação e educando, espaço escolar, materiais didáticos e prática docente. Desenvolvido no auditório do Câmpus de Cametá, contou com a participação de 16 professores (de escolas públicas) e alunos (de graduação).

No segundo semestre de 2011 as atividades do projeto foram direcionadas em um momento inicial para a realização das oficinas de preparação de materiais didáticos. Nestas, os participantes foram distribuídos por áreas temáticas de estudo, sendo trabalhadas as atividades voltadas para a produção de materiais didáticos e permitida a discussão sobre a prática docente na distribuição de conteúdos e estruturação curricular das escolas em que os professores 
atuavam. Para esta etapa de desenvolvimento do projeto foram utilizadas 40 horas de carga horária, sendo que as temáticas das oficinas estavam voltadas para a construção de jogos no ensino de história, uso de documentos na prática docente, construção de textos didáticos e imagens e filmes nas aulas de história. Foram inscritos cerca de 10 professores e alunos em cada oficina, totalizado 48 participantes.

\section{Resultados e Discussão}

Os resultados das oficinas e encontros foram compartilhados no III Momento de Diálogos Científicos do Câmpus Universitário do Tocantins/Cametá, em dezembro de 2011. Os bolsistas do projeto colaboraram ainda com a pesquisa de campo desenvolvida na comunidade do Pacajá, próximo da cidade de Cametá. Nesta atividade auxiliaram na elaboração de uma planilha que buscava diagnosticar a produção oriunda da agricultura familiar, na coleta de dados junto a estas unidades de produção e a sua sistematização, que posteriormente serviriam para fornecimento de dados na elaboração de materiais didáticos sobre esta comunidade. A escola comunitária do Pacajá serviu como laboratório para aplicação de alguns recursos didáticos produzidos nas oficinas do projeto PROINT.

Com o propósito de garantir a construção de atividades associadas à produção de ferramentas e instrução da prática docente em História, por meio da elaboração de materiais didáticos como cartilhas, textos, banco de imagens, planilhas e softwares, o projeto PROINT possibilitou: 1. Identificar através de relatos dos professores da educação básica, participantes do projeto, as condições estruturais das escolas públicas em que estes docentes atuam, pois considera-se que é uma informação importante para condicionar a produção de ferramentas didáticas e metodológicas; 2. Envolver licenciandos bolsistas (quatro acadêmicos) no trabalho de monitoria e auxílio aos professores da equipe técnica do projeto; 3. Construir um quadro demonstrativo, a partir de relatos dos professores da educação básica, participantes do projeto, que objetivou identificar as metodologias de aprendizagem para o ensino de História, desenvolvidas no espaço escolar, a forma como foi apresentada, o envolvimento dos alunos e os resultados obtidos; 4. Construir um quadro demonstrativo com a frequência das metodologias de ensino, seus efeitos e possibilidades de alterações, considerando o relato dos professores da educação básica participantes do projeto; 5. Disponibilizar aos professores no segundo semestre de 2011 um conjunto de materiais didáticos desenvolvidos nas oficinas pedagógicas, a exemplo de apresentações digitais, produzidas no programa Power Point, iconografia históricas manipuladas no programa Print Script, jogos educativos (quebra cabeça com ilustrações de personagens, locais históricos e acontecimentos do passado), entre outros; 6. Assegurar a formação dos 26 professores de História que participaram dos encontros formadores e oficinas; 7. Assegurar a formação de 22 alunos de graduação por meio das atividades desenvolvidas pelo projeto; 8. Atender 26 docentes, 4 bolsistas e 22 alunos de graduação em História e Pedagogia nas oficinas de produção de materiais didáticos e sua aplicação metodológica.

A integração do projeto PROINT entre seus executores se materializou na atuação direta dos bolsistas e professores no planejamento e realização das atividades propostas para serem desenvolvidas nas oficinas de produção de materiais didáticos. Além de permitir o conhecimento das etapas necessárias que envolveram o planejamento (a exemplo da escolha de conteúdos, seleção de materiais didáticos e aportes teóricos e metodológicos), foi possível que os alunos bolsistas e professores tomassem ciência das atividades necessárias para elaboração de materiais didáticos ou transposição didática de conteúdo do ensino superior e como este trabalho podia ser desenvolvido nas atividades pensadas para as disciplinas.

Do ponto de vista da pesquisa e da extensão as atuações dos alunos bolsistas e professores consistiram no auxílio para elaboração de questionários necessários para a coleta de dados, assim como a sua devida aplicação. No projeto, esta experiência foi compartilhada com os alunos do ensino fundamental e médio, quando fizeram o levantamento das condições econômicas e a estrutura agrária presente na comunidade do Pacajá, uma das comunidades para a qual 0 projeto foi voltado, visto que uma das escolas em que as ações do projeto foram desenvolvidas fazia parte da referida comunidade.

A integração do projeto PROINT com a extensão se efetivou ainda com o contato dos alunos bolsistas com os professores do ensino fundamental e médio das escolas da região, quando da execução de tarefas associadas à experiência docente. Os participantes do projeto atuaram e conviveram nos espaços escolares estabelecendo relações e auxiliando os alunos da educação 
básica nas tarefas exigidas como requisitos de avaliação do conhecimento adquirido por esses alunos. Observa-se ainda a relação com a comunidade, quando da atuação dos bolsistas nos eventos promovidos pela Faculdade de História e pelo Câmpus de Cametá.

Com o programa os alunos bolsistas puderam atuar mais diretamente no planejamento e execução de atividades pensadas para a disciplina de História no ensino fundamental e médio, assim como permitiu que os professores organizassem suas atividades, pensando na colaboração desses bolsistas. Assim, o projeto PROINT permitiu maior democratização das decisões quanto à escolha de conteúdo e estratégias de sua execução. 0 envolvimento dos alunos bolsistas garantiu também melhor rendimento na avaliação, o que foi também resultado de maior tempo de dedicação às atividades acadêmicas.

Através do projeto PROINT observou-se maior relação do curso de graduação com as demandas sociais, visto que esses bolsistas também se envolveram em atividades que intervinham diretamente na comunidade e ainda compartilhavam com a sociedade essas experiências, trazendo problemáticas sociais para dentro da universidade, redimensionando, inclusive, as propostas inicialmente pensadas para atividades curriculares do curso de graduação.

Do ponto de vista teórico, não há dúvidas de que os avanços foram significativos. Foram observadas melhorias na apropriação de conceitos, quanto ao ensino e aprendizagem, leitura escolar, plano de aula, plano de curso, projeto pedagógico, planejamento de ensino e outras temáticas conceituais que envolveram a formação docente em História. No campo dos experimentos, a possibilidade de elaborar propostas de intervenção na sociedade, como oficinas, também foi significativo. Acrescenta-se ainda a possibilidade de atuar na organização e desenvolvimento de tarefas relacionadas à produção de evento acadêmico, o que permitiu, além de um senso de organização, a capacidade de articular interesses da academia com os da sociedade.

Em outra perspectiva de avaliação, considera-se relevante as visitas às comunidades ribeirinhas e o contato com essa população, conhecendo inclusive o processo de exploração do solo e dos recursos florestais desenvolvidos por essas comunidades.

Com relação às intervenções didáticas e científicas, foram estabelecidas no processo de planejamento de atividades para as disciplinas e no planejamento dos eventos e oficinas. Além disso, foram vivenciadas no espaço da sala de aula, com a colaboração dos bolsistas na execução dessas tarefas planejadas para serem desenvolvidas junto aos discentes ou à comunidade. Afirma-se, portanto, que estas ações sofreram interferência dos bolsistas não apenas quando da sua elaboração, mas também na sua execução.

Existiu ainda intervenção do programa de monitoria junto à sociedade, observada nos momentos das atividades de atuação mais direta na comunidade. Um dos exemplos foi quando foram desenvolvidas ações voltadas para diagnosticar as unidades de produção familiar junto à comunidade do Pacajá. No entanto, é possível perceber uma intervenção menos direta, quando os bolsistas foram chamados para auxiliar no planejamento de atividades a serem executadas nas disciplinas do curso de História. Isto se efetivou quando os bolsistas trouxeram demandas da própria sociedade para serem incluídas nas atividades das disciplinas e quando a proposta do programa se voltou para pensar as atividades dos bolsistas a partir da realidade da comunidade em que o curso está sendo desenvolvido e a partir da realidade do próprio bolsista.

Se fosse para apontar os pontos positivos deste projeto destacaria-se: 0 envolvimento dos alunos bolsistas com planejamento e execução de tarefas associadas às reuniões de formação e oficinas de produção de materiais didáticos; a possibilidade de estabelecer diálogo entre bolsistas e docentes de graduação, quanto ao planejamento e execução de atividades acadêmicas; a possibilidade de convivência dos bolsistas com as comunidades ribeirinhas da região; a vivência de experiências docentes nos espaços escolares de ensino básico.

Como questões que limitaram o desenvolvimento de algumas atividades do projeto apontamse: dificuldades na aquisição de leituras pertinentes à temática do ensino de História, pelo escasso acervo bibliográfico presente na biblioteca do Câmpus de Cametá; número reduzido de computadores na sala de informática do Câmpus de Cametá; e utilizado para planejamento de atividades pertinentes as atividades do projeto; dificuldade de acesso à informática, 0 que impossibilitava que documentos fossem baixados da rede mundial de computadores, sendo estes documentos importantes quando da leitura necessária para planejamento de atividades acadêmicas. 
Figura 1: Reuniões preparatórias.

Fonte: Acervo particular dos autores.

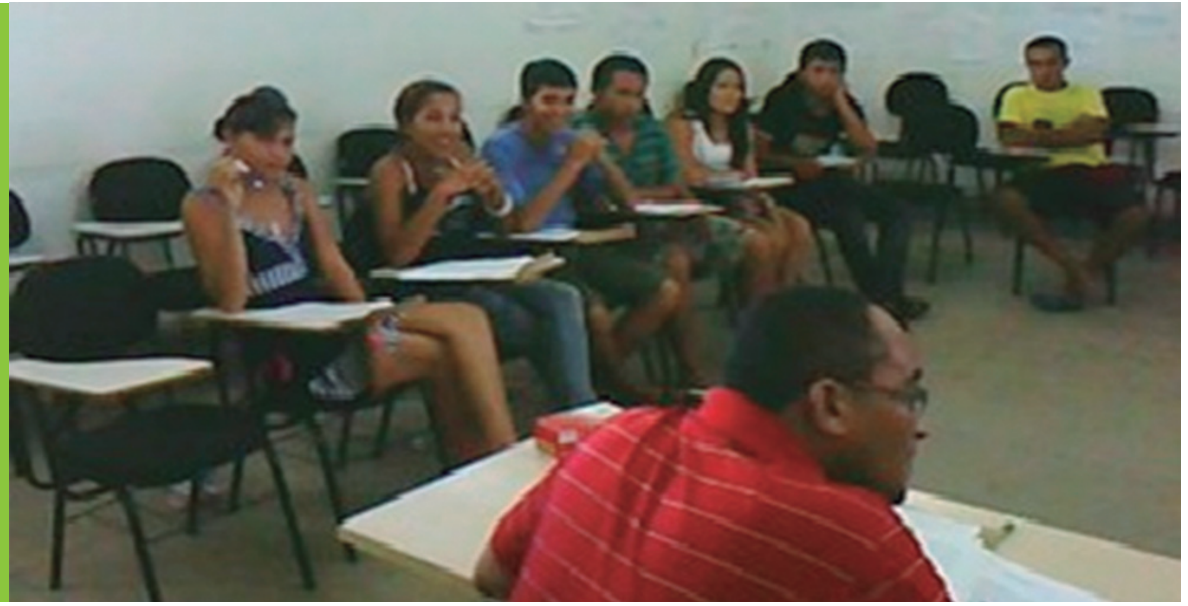

Figura 2: Bolsistas em atividades de campo.

Fonte: Acervo particular dos autores.

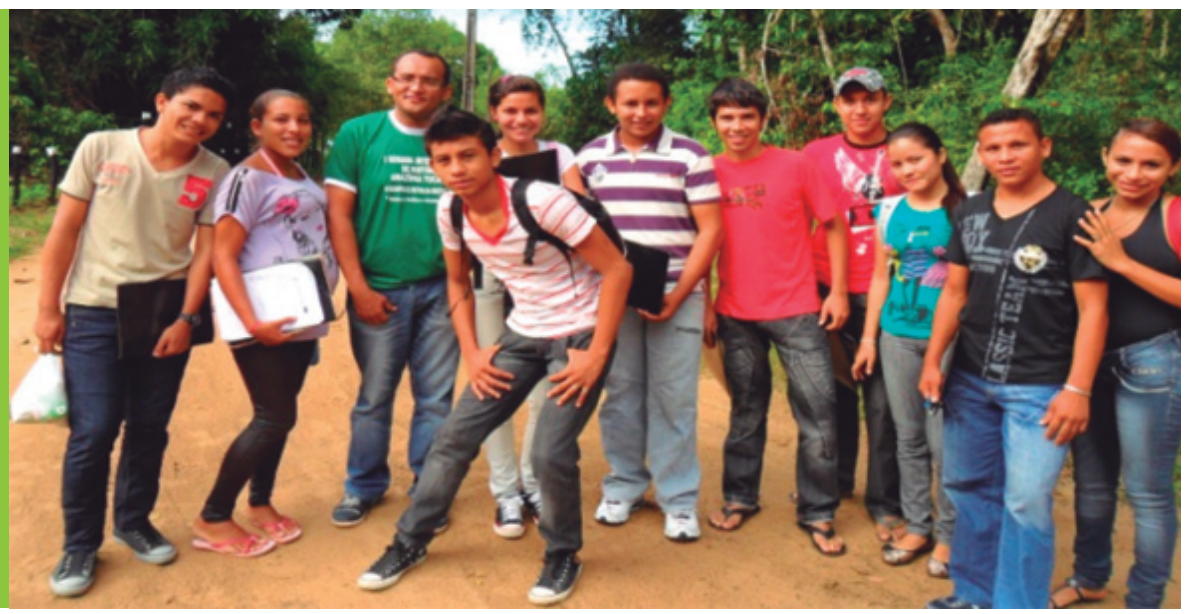

Figura 3: Alunos do ensino fundamental em atividades.

Fonte: Acervo particular dos autores.

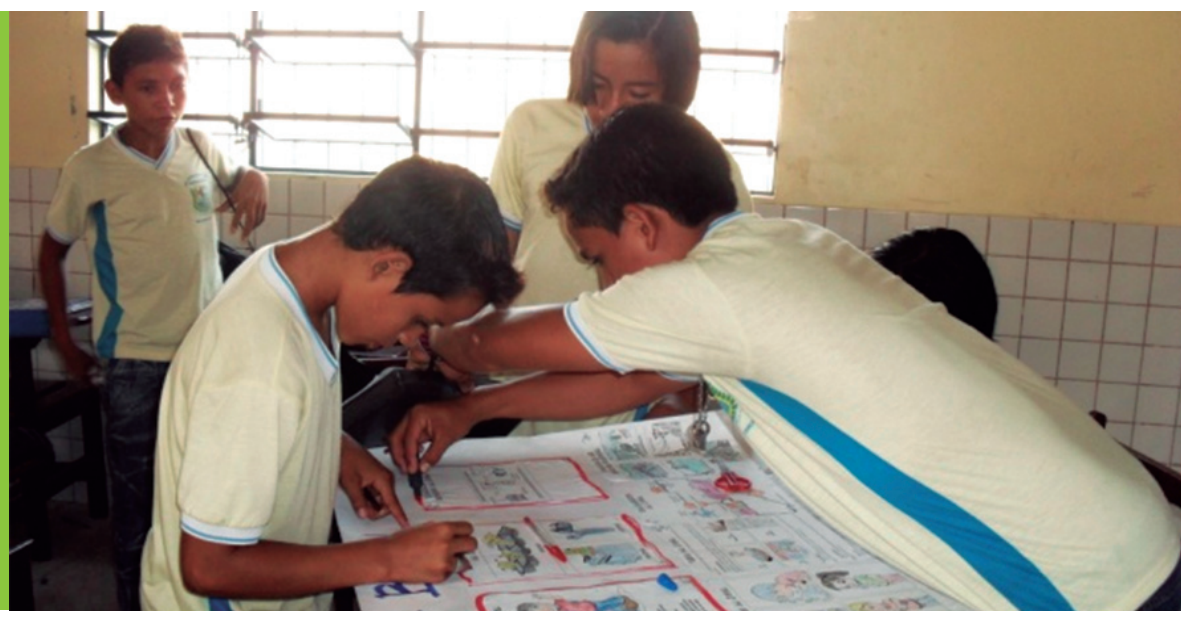

\section{Conclusões}

0 exercício de atividades voltadas para o ensino, pesquisa e extensão, desenvolvido através do projeto PROINT, possibilitou de maneira integral e sistemática a iniciação do aluno bolsista na experiência docente e em condições estruturais vivenciadas pelas escolas públicas do município de Cametá, oferecendo-Ihes as condições necessárias para que pudessem aprofundar os conhecimentos na disciplina de História de forma a pesquisar, elaborar, redigir e apresentar procedimentos experimentais sobre o conteúdo da disciplina, através do auxílio ao desenvolvimento de atividades acadêmicas.

Quanto à atividade de ensino estabelecida pelo bolsista, esta se constituiu enquanto processo que se caracterizou pelo desenvolvimento e transformação progressiva das capacidades intelectuais dos alunos bolsistas em direção ao domínio do conhecimento, habilidade e sua 
aplicação. Por isso, obedeceu a uma direção, orientando-se para objetivos conscientemente definidos, o que implicou passos gradativos de acordo com critérios de idade, preparo dos alunos e nível de atenção.

As atividades do projeto PROINT se referiam ainda a ações extraclasse que buscavam resgatar dificuldades que ocorrem no processo de ensino-aprendizagem na sala de aula e propor medidas para solucioná-las, não devendo ficar restritas a um único foco. 0 professor desenvolveu junto ao aluno bolsista estratégias para o melhor aproveitamento do processo ensino-aprendizagem, proporcionando aos estudantes mais oportunidades de discutir o conteúdo teórico e prático trabalhado no curso de História.

Durante os encontros formadores e oficinas de produção de materiais didáticos, a metodologia aplicada mediante planejamento envolveu os diferentes modos de retransmissão e compartilhamento do conteúdo, como aulas expositivas face aos recursos disponíveis, além de grupos de discussão e estudos dirigidos envolvendo discussões interdisciplinares e resolução de problemas. Utilizaram-se também exemplos práticos contidos em experiências de laboratório com o propósito de produção de materiais didáticos pertinentes às temáticas trabalhadas na disciplina. Para a atividade individual o recurso utilizado foi o diálogo, extraindo as pequenas ou grandes dúvidas ainda existentes, com o auxílio de uma literatura adicional, além da fornecida pelo professor.

A metodologia desenvolvida pelo projeto, se por um momento exigiu o domínio do conteúdo da disciplina de História, principalmente pelos professores, por outro, permitiu capacitar para retransmissão do conteúdo e habilidade nos procedimentos didáticos expostos para motivar 0 aluno no processo de decodificação da disciplina, permitindo o aprofundamento teórico e a reflexão sobre os temas abordados. Ao adicionar elementos novos à aula expositiva, os alunos são levados a desenvolver sua capacidade crítica em vez de decorar os conteúdos, obtendo um aproveitamento mais significativo da disciplina, auxiliando na fixação do conteúdo, reduzindo assim suas deficiências e despertando 0 interesse pela atividade científica.

Não há dúvidas que as atividades desenvolvidas pelo projeto PROINT auxiliaram na melhoria da qualidade do processo ensino-aprendizagem, estreitando a relação professor-aluno, ao mesmo tempo em que contemplou e inseriu a figura do bolsista na prática do exercício da docência e da formação didática, abrindo o caminho da socialização do saber acadêmico.

\section{Referências}

BRASIL. Ministério da Educação, Secretaria de Educação Média e Tecnológica. Parâmetros Curriculares Nacionais: Ensino Médio. Brasília: MEC, 1999.

CORREA, Paulo Sergio de Almeida \& BARRETO, Edna Abreu. 0 Ensino Médio no Estado do Pará segundo as estatísticas oficiais: Os impasses das políticas públicas educacionais e os desafios para 0 século XXI. In: Paper do NAEA 122, agosto de 1999, pp. 1-40.

PINSKY, Jaime (org.). $\mathbf{0}$ ensino de história e a criação do fato. São Paulo: Contexto, 2006.

SALIBA, Elias Thomé. A produção do conhecimento histórico e suas relações com a narrativa fílmica. In: Coletânea Lições Com Cinema, São Paulo, FDE, 1993, pp. 87-108.

SILVEIRA, Rosa Maria Godoy. Conferência: A formação do Profissional de História para 0 século XXI. XI Encontro Estadual dos Professores de História (Associação Nacional de História/Núcleo Regional da Paraíba). João Pessoa, 2007.

SOUZA JÚNIOR, João Batista Rodrigues de. Política de Interiorização da Universidade Federal do Pará (UFPA): diretrizes do Reuni na Amazônia Tocantina/Cametá/Pa. Trabalho de Monografia apresentado ao Curso de Pós Graduação Lato Sensu em Gestão e Planejamento da Educação Faculdade de Educação Campus Universitário do Tocantins/Cametá (CUNTINS)/ Universidade Federal do Pará (UFPA). Curso de Especialização, 2012.

TARDIF, Maurice. Saberes docentes e formação profissional. 2. ed. Petrópolis, RJ: Vozes, 2002.

VYGOTSKY, L. S. Pensamento e Linguagem. São Paulo: Martins Fontes, 2000. 